ginning to appreciate the extent and variety of the ravages of remote syphilis in the internal organs.

This disease can be restricted, not by licensing prostitutesalready proven a failure in Europe-nor by educating youth to chastity, for this laudable effort is proved impotent against the polygamous instinct of the mammalian male; but by making the acquisition of syphilis by the male practically impossible through circumcision.

It is notorious that Jews furnish relatively few cases of syphilis; that this immunity is not due to their superior continence is shown by their frequent acquisition of gonorrhea; that it is due to the hardening of the puerile covering through early circumcision, and consequent freedom from abrasions during intercourse, is obvious. This rarity of syphilis is observed among all circumcised races-whether Mohammedans, Buddhists or (Abyssinian) Christians. The early Egyptian practice of circumcision just before puberty is one of several facts which suggest that the general adoption of circumcision by the early Semitic races was for protection against syphilis.

The evils of remote syphilis can be reduced by impressing on the syphilized two injunctions: 1, To take antisyphilitic remedies for two months in each year after the termination of active treatment; and 2, to inform any physician who may at any time be consulted for relief from a chronic ailment, of the early syphilitic infection. WM. T. BELFIELD.

\section{Co-ordination in Government Medical Service.}

To the Editor:-It would be an excellent thing could the Committee on Legislation of the American Medical Association study the medical services of the United States as to the number of men employed, the character of the work done, results attained, together with the costs in money outlay. These medical men will be found, $I$ think, as follows:

Marine-Hospital Service, Navy Medical Department, Army Medical Department, doing biologic work in the Department of Agriculture (see the work of Stiles on human parasitology, Atwater's food and calorimetric studies on man), in the Department of the Interior as medical examiners in pension eases; and it is possible that there are yet others in the Census Bureau as statisticians in medical statistics. Then, with a summary of this work, its costs and efficiency: the faults and failures of the present system.

This study will show that there are employed in various capacities by the general government some 2,000 or 2,500 medical men, serving under at least four and perhaps more secretaries of the presidential official family. The force is scattered and no one department can legally call on another for medical assistance; the hospitals, libraries, laboratories and schools are duplicated and triplicated; they are without a common medical head, but each subdivision has its own head, a layman without knowledge of medicine, through whom the department reports to the President, the executive head of the nation. What opportunity has the President under such conditions to obtain a comprehensive working knowledge; to enable him to co-ordinate the medical information he has received with the reports of other conditions which he receives from his other secretaries from the same point, when receiving such a report from a man who is unable to explain to him the points which are not clear?

What would have happened to the United States when the bubonic plague made its appearance in San Francisco, had it not been for J. J. Kinyoun's work? This dread disease would have spread over the entire United States, and would have cost the United States many times the money paid out for the entire medical service from the foundation of the government to the present; as it was, the interstate law enabled the P. H. \& M.-H. Service to force, through the operation of interstate quarantine, a partial compliance with sanitary obligations which resulted in stamping out the disease. The business men of California almost succeeded in allowing their greed for money to infect the entire country with this disease.

Having had these studies and compilations made, calculate, on current prices, the costs, etc., of a new Department of Public Health, with a secretary of public health a medical man, to be chosen by the President from the public at large, who is engaged in the active practice of his profession, and confirmed by the senate. Consolidate all medical service to the United States under this secretary of public health, consolidate the hospitals, libraries, laboratories, and schools from their present semi-chaotic state, make up your costs and comparisons in dollars, and the saving in actual money will be very large.

Then compare the efficiency in applying laws relating to food supplies, medicines, water supplies, in controlling threatened epidemics, the ability to meet sudden calls on the medical service of the United States, like that which existed in 1898, when 250,000 men were called for the Army and many for the Navy. Under the conditions mentioned, there would have been a large number of trained men who could have at once gone to the front, while their civilian brothers would have replaced them in post hospitals, the marine hospitals, laboratories, etc., where they would have worked acceptably to themselves and the government, the rush being slight, and the work almost that to which they are accustomed in civil life, while these men, trained in public health technic, understanding the necessary red-tape of the department, took the rough end of the work at the front, meanwhile training their civilian brother into the red-tape (administration work) of the public health official, as might fall in either the Army, Navy or Marine-Hospital Service.

These medical men to be in no way responsible for their work to the military or naval commander, and having in no way any control over either soldier or sailor, when not in hospital, but to be the representative of, and reporter to, the President on all sanitary and medical questions in the army or navy, and as the executive in all international, interstate and interisle and quarantine matters, and as such the representative of the executive in all medical matters, reporting direct all insanitary conditions which may threaten the country or the country's forces, to the executive at the center; who can then balance the report with other reports and issue such orders as he may see fit; with sanitary conditions considered as are other conditions, the Secretary of Public Health explaining to the President what the conditions reported threatened to the command or to the country at large.

To leave medical men in their present condition of subordination to men who know nothing of these matters is to result in medical men reporting conditions just far enough to enable them when bad results come, to point to the report and say: "I reported the facts and pointed out the dangers"; for the responsible man to say: "I am no doctor, I did not understand the force of the report; I exercised my best judgment," and nobody is responsible. Meanwhile men die, the costs go mounting up, an epidemic is well under way, and nobody is responsible; the medical man, because he advised the executive, because he did the best he knew how, and all join hands to call the failure to fix the responsibility a visitation of God, and to say that it was impossible to avoid.

The local boards of health attain the results aimed at, whereas failure to obtain them is the universal history of all armies in war and peace.

With this should go also a public health medical school, to which young graduate medical men and graduate nurses should be sent to receive a postgraduate course, of two or three years, to train them in the laws and customs of this highly specialized service, which has been so much neglected by the profession at large, namely, caretaking of the public health.

To sum up then, it would appear that an excellent formation for this purpose would be: A secretary of public health, a cabinet officer; A public health medical service, to be composed of: Medical officers, graded, and nurses, clerks, mechanics, and laborers, all graded and classified; and lastly a public health medical school, in which to train all medical men and nurses in this service, and to which they should be re turned for study from time to time, and from which entry into the Public Health and Marine-Hospital Service is to be made, after the original formation of the service.

It has been suggested that the same end might be attained by transferring the three present departments to a public health department and keeping the present men at their present 
work, and let the change come little by little, all new appointments to be made in the public health service, and thus save heart burning. WEN. Woo.

\section{Querles and MInor Notes.}

Anongmous Commitications will not be noticed. Queries for this column must be accompanied by the writer's name and ad. dress, but the request of the writer not to publish his name will be falthfully observed.

\section{VOMITING IN PREGNANCY.}

Nebrasisa, June 7, 1904

To the Editor:-Can you give me the name of some good remedy for vomiting, especially the vomiting of pregnancy? I have had several cases during the last vear and have failed miserably of success. I have tried the most common remedies without effect : nux rom.. cerium oxalate, pepsin, ingluvin, bromids, bismuth, ipecacuanha, mercury, oplum, lime water, etc.

M. M.

AYSTRB-Vomiting of pregnancy has been ascribed to many causes, and many remedies and methods of treatment have been recommended to combat it. Recently a number of obstetricians bave been inclined to ascribe it to an intoxication of the maternal organism by fetal or placental products. Whatever may be the underlying canse there can be no doubt that sources of peripheral irritation, like 2 dilated and inflamed stomach, a constipated bowel, tight corsets, a retroverted and retroflexed uterus, etc., are very important accessory factors. In accordance with this vlew of the etiology the management should consist in removing carefully and as thoroughly as possible all the complicating factors. The diet should be carefully regulated, if necessary the stomach washed out, the bowels well emptied, a displaced uterus replaced and all constricting bands or corsets removed. If the vomiting is severe or continuous the patient should keep in a horizorital position, and in bad cases she shouid receive rectal injections of alcohol and salt solution. In all cases a hot drink in the morning some time before rising is desirable. Drugs play a very secondary rôle in the treatment. Laxatives are sometimes necessary, as indicated above. Bicarbonate of soda or bismuth, etc. may sometimes have a temporary value. There is, however no specific or "sure cure." That physician will have the best success in managing these cases who searches out the important etlologic factors and removes them. The nervous element is especially important in these cases, and the physician who has a confident and masterly presence and carriage, one who believes in himself and his ultimate success, has a great advantage.

\section{THYROID ENLARGEMFNT.}

Seattue, Wash, May 26, 1904

To the Editor:-Does the following patient require treatment and should she remain single: Female, 24 years old, has had a small enlargement of the thyroid gland for the past twelve years. Sometimes it enlarges slightly, but soon recedes. General health is good, not nervous nor hysterical. No protrusion of the eyes and pulse about $\Omega 0$. If she requires treatment, what would you suggest? One year ago she moved from the middle states.

A. J. $\mathbf{H}$.

Answer.- The careful investigations of Lange of Koenigsberg, published in 1899 , have confirmed the idea long held that there is generally an enlargement of the thyroid gland during preg. iancy. Lange found that this enlargement appears during the fifth or sixth month of pregnancy and disapnears seven to four teen days after labor. He also has found an interesting connection between the hypertrophy of the thyroid and the action of the kidney. In 25 cases where there was no enlargement of the thyroid, out of 133 examinations, he found albumin in the urine 18 times. In none of the cases of thyroid hypertrophy was there albumin or evidence of the existence of kidney disease characteristlc of pregnancy. In cases of kidney disease with albumin the administration of lodo-thyroidin imploved the urinary secretion and decreased the amount of albumin. In his experiments on cats that also have thyroid swelling during pregnancy he showed that if more than $4 / 5$ of the thyroid was removed from pregnant animals tetany occurred that was favorably influenced by the administration of thyroidin or lodo-thyroidin. A greater amount of thyrold tissue must be left in a pregnant animal than in one nonpregnant to preserve its health. If a large amount, but less than $4 / 5$ of the thyrold gland be removed, the kidney undergoes parenchymatous degeneration and the animal falls into convulsions or a state of coma. Lange concludes from these observations and experiments that there is produced during pregnancy, probably by placental metabolism, a substance that stimulates the thyroid to increased growth and activity resulting in an increased thyroid secretion containing antloxic properties. If this fails the kidneys have extra work to do and are apt to suffer as a result. If this theory be true, it rollows that thyroid disease or insufficiency may be of serious consequences in pregnancy. It is not probable, however, that a case of slight enlargement like that reported in the Inquiry would have any serlous importance. There seems to be no insufficiency of gland secretion at present. Probably some physiologlc hypertrophy would take piace during pregnancy. Whether this would be so great as to cause a mechanical obstruction to respiration can not be foretold, but in case such a symptom should arise It could be controlled by the use of thyroidin. Hence we should answer that there is no ground for forbldding marriage in this case, nor shonld we anticipate trouble during pregnancy. It would be the part of prudence in case of a supervening pregnancy to keep the patient under observation, and if necessary administer iodo-thyroidin in doses of 10 to 25 grains a day. Otherwise no medication would be required.

\section{DOCTOR PAYS FUNERAL EXPENSES.}

A colrespondent has favored us with an advertisement which appeared in the printed program of an athletic meet in Minnesota, and which is worthy of reproduction. We, therefore, print it free

$$
\text { DR. W-. C- }
$$

Funeral Expenses Paid and No Fee Charged in the event of death from Diphtheria and Typhoid Fever.

\section{Therapeutics.}

[Our readers are invited to send favorite prescriptions or outlines of treatment, such as have been tried and found useful, for publication in these columns. The writer's name must be attached, but it will be published or omitted as he may prefer. It is the aim of this department to aid the general practitioner by giving practical prescriptions and, in brief, methods of treatment for the diseases seen especially in everyday practice. Proper inquiries concerning general formulae and outlines of treatment are answered in these columns without allusion to inquirer.]

\section{Sodium Bicarbonate in Gastric Troubles.}

Huchard, in an abstract in Jour. Amer. Med. Sciences, states that sodium bicarbonate is indicated in small doses (3 to 5 grains, .20-.30), taken one-half hour before eating, in the treatment of anorexia, as it increases the secretion and excites the contractility of the stomach. He prefers it to the bitters. In hyperchlorhydria it is indicated in large doses at the end of the period of digestion, two or three hours after a meal, when the gastralgia is likely to occur. In this latter condition he recommends it in 4 or 5 dram (15.-20.) doses daily for several weeks, and states that he has seen no evil effects from its use in such doses; on the contrary, oxidation and metabolism are favored and an increase in body weight. The gastric crises of tabes, when accompanied by hyperehlorhydria, respond to the sodium bicarbonate given in 5-dram doses (20.) per day. He thinks it is the remedy par excellence in diabetes, in the prevention of coma, which condition is characterized by true acidemia. The dosage in this disease should be at least 2.5 drams (10.) daily, and where coma exists as large a quantity as three ounces may be given. In dermatoses of arthritic origin, alkaline medication is indicated, giving the sodium bicarbonate in 3 or 4 -dram doses (12.-15.) per day. In biliary lithiasis and hepatic colic one of the surest methods of cure, according to the author, is alkaline medication employed in large doses.

In gastric dilatation accompanied by hyperchlorhydria, Sow pault, in Jour. de Méd. de Paris, recommends the following:

R. Sodii bicarb.

Cretæ prep.

Bismuthi subnit., $\bar{a} \bar{a} \ldots \ldots \ldots \ldots$ gr. viiss

Magnesiæ (calcined) .............gr. v

M. Ft. chart. No. i. Sig.: One such powder every three hours.

And for the constipation:

R. Sodii phos. ................gr. $\mathrm{lxxv}$ Sodii bicarb. ....................

Sodii sulph. .................. xlv 3

M. Ft. chart. No. i. Sig.: One such powder dissolved in a quart of water, and take a glassful each morning on rising.

\section{Camphor Hypodermically.}

J. I. Johnston, in Med, states that camphor is a valuable cardiac stimulant, even as good or better than strychnia. In 